УДК 902.01; 903.33; 903.42

https://doi.org/10.24852/2587-6112.2020.5.182.197

\title{
МАЛЬЦЕВСКАЯ ІV СТОЯНКА ПОЗДНЕГО БРОНЗОВОГО ВЕКА НА Р. ТОЙМА В НИЖНЕМ ПРИКАМЬЕ
}

\author{
(C) 2020 г. А.В. Лыганов
}

B статье публикуются результаты охранно-спасательных исследований на Мальцевской IV стоянке, расположенной на невысокой пойменной дюне в нижнем течении р. Тойма, правого притока

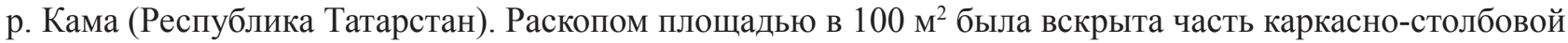
постройки и хозяйственные ямы поселения. Весь керамический материал стоянки из слоя и заполнения ям относится к луговской культуре позднего бронзового века Волго-Камья (XVII - XV вв. до н.э.). Эти данные позволяют сделать вывод об однослойном характере памятника. Судя по расположению, мощности культурного слоя и некоторым особенностям построек, автором делается предположительный вывод о сезонном характере Мальцевской IV стоянки, связанном с выпасом крупного рогатого скота, которым занимались ее обитатели.

Ключевые слова: археология, Нижнее Прикамье, дюна, пойма, поздний бронзовый век, луговская культура, поселение, постройка.

\section{MALTSEVO IV SITE OF THE LATE BRONZE AGE ON THE TOIMA RIVER IN THE LOWER KAMA REGION}

\section{A.V. Lyganov}

The article features the results of rescue investigation of the Maltsevo IV site located on a low floodplain dune in the lower reaches of the Toyma river, the right tributary of the Kama (Republic of Tatarstan). A portion of a frame-and-pillar structure and household pits of the settlement were uncovered at an excavation with an area of 100 square meters. All the ceramic material of the site from the layer and filling of the pits corresponds to the Lugovskaya culture of the Late Bronze Age of the Volga-Kama region (17 th $-15^{\text {th }}$ centuries BC). This data gives the author opportunity to make a conclusion about the site had a single-layer character. Considering the location, thickness of the cultural layer, and certain features of the buildings, the author suggests a seasonal nature of Maltsevo IV site, associated with the grazing of cattle, which its inhabitants were engaged in.

Ключевые слова: archaeology, Lower Kama region, dune, floodplain, Late Bronze Age, Lugovskaya culture, settlement, building.

Мальцевская IV стоянка расположена в 600 м северо-западнее северной оконечности д. Мальцево Елабужского района Республики Татарстан на правом берегу р. Тоймы, правого притока р. Камы (рис. 1). Памятник находится в пойме реки на невысокой дюне, возвышающейся на 2-3 м над ежегодно затопляемыми участками. Очевидно, в древности это было одно из самых высоких мест в пойме. Поверхность памятника, как и окружающую его территорию, покрывает луговая растительность. С севера и северо-востока территория дюны ограничена заболоченными низинами. На западной и северо-западной части дюны произрастает лес с густым подлеском. Разведочный шурф, заложенный у восточной оконечности леса, культурного слоя и каких-либо находок не выявил. С югозапада и юга площадку стоянки ограничивает заболоченная низменность, подходящая к правому берегу р. Тоймы, который находится в 60 м к югу от южной границы стоянки. На востоке возвышенность, на которой располо- жен памятник, полого снижается, переходя в невысокую длинную дюнную гряду, которая с севера ограничена протоками и старичными озерами, а с юга рекой Тойма. В 250 м к востоку от Мальцевской IV стоянки расположено еще одно дюнное возвышение, на котором также фиксируется подъемный материал эпохи бронзы. Этот участок был назван как Мальцевская V стоянка. Границы этого памятника не определялись. Возможно, это продолжается территория Мальцевской III стоянки, выявленной разведкой С.В. Кузьминых в 1971 г (Свод памятников..., 2007).

Мальцевская IV стоянка находится в археологически хорошо изученном районе приустьевой части р. Тоймы и прилегающего правого берега р. Камы. Здесь раскопами изучены Луговская I-IV стоянки, стоянка на Ананьинском могильнике, Кумысская стоянка. На каждой из Луговских стоянок вскрыто жилище или комплекс жилищ разного периода эпохи бронзы (Збруева, 1960; Генинг, Старостин, 1972, Лыганов и др., 2017). 
Мальцевская IV стоянка была открыта в 2016 году при проведении разведок по линии строительства объекта: «ВЛ 220 кВ Щелоков - Бегишево с переустройством ВЛ 220 кВ Нижнекамская - Тойма». Дневная поверхность памятника в момент проведения разведки была занята лугом, подъемный материал был выявлен только в месте нарушения культурного слоя опорой ЛЭП. Шурфами была определена граница памятника (рис. 2А). Площадь его небольшая и составляет около

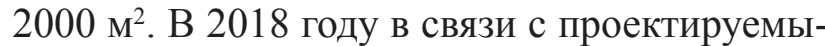
ми строительными работами на территории стоянки был заложен раскоп общей площадью в 100 м. $^{2}$

Раскоп I был заложен в центральной части стоянки (рис. 2А) в непосредственной близости от существующей платформы ЛЭП. Первоначально был разбит раскоп прямоугольной формы $14 \times 6$ м, далее вдоль восточной стенки раскопа на север и на юг были добавлены еще по два участка $2 \times 2$ м. Таким образом, раскоп имеет Т-образную форму (рис. 3 ).

Перепад высот раскопа на уровне современной поверхности составил около $50 \mathrm{~cm}$, самой возвышенной оказалась северная и центральная часть раскопа с постепенным понижением к югу и востоку.

\section{Стратиграфия раскопа следующая} (рис. 3):

- Дерн - имеет небольшую мощность около 2-4 см. Находок не содержал.

- Под дерном на северо-восточных участках A-B/1-3 выходит прослойка красно-коричневого суглинка мощностью 1-6 см. По происхождению это слой материкового суглинка, который был рассыпан и раскатан по площади стоянки в процессе установки опоры ЛЭП. Находок не содержал.

- Плотная темно-серая гумусированная супесь мощностью 15-35 см является культурным слоем стоянки. В этом слое, преимущественно в его нижней части, сконцентрировано подавляющее большинство находок стоянки (около 400 фрагментов керамики или $58 \%$ всех находок). Мощность слоя наибольшая в центральной части раскопа и на уч. B-E/4-5. Наименьшая мощность при практически полном отсутствии находок на уч. А/1 и $\mathrm{A} / 7$, то есть на северных и южных участках раскопа.

- Плотная серо-коричневая супесь подстилает слой плотной темно-серой гумусированной супеси и является переходной к материковому суглинку. Граница между слоями очень нечеткая. В этом слое выявлено около 30 фрагментов керамики или 4\% всех находок на раскопе.

- Гумусированная серая супесь с включением угольков (в разных пропорциях) является заполнением всех материковых сооружений и ям. Этот слой, как заполнение сооружения 1, хорошо фиксируется в профилях на уч. Д-Ж/4-5. Мощность его составляет от 2-3 до 35 см. В заполнениях всех сооружений раскопа выявлено 256 фрагментов керамики или $38 \%$ всей керамики раскопа.

- Красно-коричневый суглинок (материк) - вскрыт на разных участках на глубину 5-15 см.

\section{Сооружения и ямы раскопа}

На раскопе были выявлены остатки каркасно-столбовой постройки с заглубленным полом (сооружение 1), четыре ямы различного назначения и 27 столбовых ям.

Сооружение 1 (рис. 2Б, 3) Первые очертания сооружения были зафиксированы после снятия первого пласта, однако сильно гумусированное пятно здесь не имело четких очертаний. Четкие границы были зафиксированы на уч. Д-Ж/4-5 на глубине -126-144 см от 0 (после зачистки второго пласта) в виде аморфного пятна гумусированной серой супеси с включением угольков, уходящего в северную и западную стенки раскопа. Размеры исследованной части сооружения составили $586 \times 310$ см. Площадь вскрытой раскопом части постройки составляет около $18 \mathrm{~m}^{2}$. Ориентировано сооружение по направлению юго-восток - северо-запад. Профили сооружения были зафиксированы в северной и западной стенке раскопа и в разрезе по линии запад-восток. Находки представлены большим количеством лепной керамики (168 фрагментов), среди которой фиксируются развалы нескольких сосудов (рис. 7). Глубина постройки от уровня выявления на материке составила 3-35 см. Дно покатое, постепенно понижается к центру сооружения, стенки не выражены. По всей видимости, мы имеем дело с незначительно заглубленной в землю постройкой, супесчаное дно которой просело в результате утаптывания людьми или животными. После выборки заполнения котлована сооружения на материке были выявлены округлые остатки от столбовых ямок. Столбовые ямки расположены по периметру сооружения, с концентрацией в его полностью исследованном юго-восточном углу. Таким образом, мы имеем дело с незначительно заглублен- 
ной в землю постройкой каркасно-столбовой конструкции с утоптанным полом. В жилище не выявлено следов очага.

Аналогии таким постройкам эпохи бронзы в Прикамье имеются в древностях прежде всего луговской культуры, памятниках балымско-карташихинского типа и отчасти атабаевского этапа маклашеевской культуры (Халиков, 1980, табл. Б, В; Чижевский, 2007, табл. 1, 2). При этом жилища на Луговских I-IV стоянках, которые находятся ближе всего к Мальцевской IV стоянке, отличаются: большей глубиной (до 80-90 см), наличием практически в каждом жилище очагов, гораздо меньшим количеством столбовых ям, мощным культурным слоем. Сами Луговские стоянки расположены на надпойменной террасе в отличие от Мальцевской стоянки, находящейся на дюне в пойме. Все это позволяет сделать предположительный вывод о разной хозяйственной направленности стоянок. Вероятно, Мальцевская IV стоянка относится к категории временных поселений и использовалась только в летние время для выпаса и содержания крупного рогатого скота (т. н. летний лагерь - летник).

Яма 1 выявлена на уч. A/5-A/6 на глубине -121 см от 0 после зачистки второго пласта в виде нечеткого округлого пятна гумусированной серой супеси с включением угольков диаметром около 40 см. Глубина ямы от уровня выявления 17 см. Дно зафиксировано на глубине -138 см от 0 . Первоначально яма была интерпретирована как столбовая. Стенки плавно сужаются к центру. Все сооружение заполнено керамикой. Это развал сосуда и скопление керамики от 6-7 сосудов (28 фрагментов) (рис. 8) По назначению яма, вероятно, является столбовой или хозяйственной.

Яма 2 выявлена на уч. Б-Г/3-4 на глубине -125-126 см от 0 после зачистки второго пласта в виде пятна гумусированной серой супеси с включением угольков, неопределенной формы, размерами около $340 \times 180$ см. Глубина сооружения от уровня выявления 2-15 см, дно корытообразное, стенок не зафиксировано. Всего в яме выявлено 49 фрагментов керамики В северо-восточной части на материке выявлен развал лепного сосуда луговской культуры (рис. 6: 2, 5, 8). Яма 2 по своему происхождению, видимо, является утоптанным в материк культурным слоем стоянки.

Яма 3 выявлена на уч. А-Б/3-4 на глубине -126-129 см от 0 после зачистки второго пласта в виде пятна гумусированной серой супеси с включением угольков, неопределенной формы, размерами около $166 \times 174 \mathrm{~cm}$. Глубина сооружения от уровня выявления 2-8 см, дно корытообразное, стенок не зафиксировано. В северо-западной части ямы на материке зафиксировано углубление (столбовая ямка?) (рис. 3). Выявлено 6 мелких фрагментов керамики луговской культуры позднего бронзового века. Яма 3 , как и яма 2, по своему происхождению, возможно, является утоптанным в материк культурным слоем стоянки.

Яма 4 выявлена на уч. A/7 на глубине -130-132 см от 0 после зачистки второго пласта в виде пятна гумусированной серой супеси с включением угольков, полукруглой формы, размерами около $26 \times 64$ см. Яма 4 уходит в восточную стенку раскопа. Глубина сооружения от уровня выявления 10-13 см, дно уплощенное, стенки почти вертикальные. При прокопке второго пласта, в верхней части сооружения, на глубине -127 и -128 см от 0 были зафиксированы индивидуальные находки: маленький сосудик баночной формы и фрагмент напрясла срубного типа (рис. 6: 3, 9). Ниже, на глубине -133-140 см от 0 при выборке сооружения было зафиксировано 6 фрагментов керамики луговской культуры. Назначение сооружения установить сложно ввиду его слабой изученности в раскопе (вероятнее всего, это хозяйственная яма).

Кроме основных сооружений на раскопе было выявлено большое количество столбовых ям (27) (рис. 3). Столбовые ямы в основном относятся к сооружению 1 и являются основой его каркасно-столбовой конструкции. Столбовые ямки 13, 17-20 22-23 и, возможно, ямки 10-12, 27-28 находятся сразу за очертаниями котлована сооружения 1 . Столбовые ямки 14-16, 21, 24-26 находятся внутри контура жилища на покатом склоне к центру постройки. Одной из центральных является столбовая ямка 16, находящаяся ближе всех к вероятному центру сооружения 1. Вероятно, столбы, расположенные в ямах 14, 16, 18-20, 24-26, имели несущую функцию в каркасно-столбовой конструкции сооружения 1. Это подтверждается как их диаметром, так и их глубиной. Столбы, расположенные в ямках 10-15, 17, 22-23, вероятно, имели второстепенное значение для конструкции. Ямки от этих столбов гораздо меньше по диаметру и глубине. В разрезе эти ямки зачастую скошены под углом. 
Кроме этого, ряд столбовых ям, возможно, являются остатками каких-то ограждений-заборов, так как они расположены по линии север-юг на относительно равном друг от друга удалении. Так, столбовые ямки 1-5, 9 вытянуты по линии квадратов $\mathrm{A} / 1-\mathrm{A} / 7$ и, вероятно, относятся к одному ограждениюзабору. Линия столбовых ямок 6-8 и 10-12, 27-28 вытянута по линии Г и образует, вероятно, другую линию ограждения-забора.

Только в одной из столбовых ямок, кроме ямы 1, которая тоже может быть условно отнесена к столбовой, выявлены находки керамики. Это столбовая яма 4 с пятью фрагментами керамики.

Вещевой материал раскопа представлен фрагментами керамики, глиняным напряслом, развалами керамических сосудов. Кремневых орудий не выявлено.

Керамический комплекс раскопа (рис. 4-8). Всего было выявлено 685 фрагментов керамики.

На первом пласте на глубине 0-20 см в слое плотной темно-серой гумусированной супеси было выявлено 68 фрагментов керамики; на втором пласте в слое плотной темно-серой гумусированной супеси и в верхней части плотной серо-коричневой супеси на глубине 20-40 см было выявлено 355 фрагментов. Керамика была зафиксирована в материковых ямах сооружения 1 , ямах 1-4, столбовой ямке 4. Подробное распределение керамики по слоям и объектам раскопа представлено в табл. 1.

Керамика, найденная в раскопе, представлена фрагментами лепных сосудов. Большинство из них составляют стенки (582 экз.) и венчики (81 экз.). Встречены днища и придонные части (22 фрагмента). Практически все венчики сосудов имеют отогнутый наружу край. Такие венчики, по мнению Ю.И. Колева, могли получаться в результате перевертывания сосуда вверх дном при просушке (Колев, 1999 , с. 253). Также встречаются венчики со скошенным наружу и простроенным краем. В составе формовочных масс керамики прослеживается шамот и песок, редко примесь раковины, в небольшом количестве. Поверхность фрагментов чаще бугристая, редко заглаженная. Большинство фрагментов имеют желтовато-серый или красно-коричневатый цвет. Толщина стенок сосудов относительно небольшая и составляет $0,5-0,8 \mathrm{~cm}$. Все днища плоские (22 экз.) и неорнаментированные. Почти на всех венчиках зафиксирован орнамент. Орнамент состоит из различных элементов: это горизонтальные линии, ряды косопоставленных оттисков гребенки, небольшие вдавления, ямки, горизонтальная елочка, заштрихованные косоугольные треугольники. В целом керамика из раскопа схожа между собой по орнаментации, примесям, формам венчиков (табл. 2). Отсутствуют венчики с рельефными валиками и воротничками, характерные для более позднего времени. Исходя из этого, можно считать памятник однослойным, что достаточно редко встречается среди поселенческих памятников Прикамья. Наиболее близкие аналогии прослеживаются в материалах Луговской I стоянки, расположенной в 5 км южнее на террасе правого берега р. Камы (Збруева, 1960; Лыганов и др. 2019, рис. 11-20). Среди других памятников, наиболее близких Мальцевской стоянке по керамическому материалу, следует выделить Кумысскую стоянку, Агидельское поселение и другие памятники эпохи бронзы Прикамья (Генинг, Старостин, 1972, рис. 5; Обыденнов, 2006 , рис. 1-4; Чижевский и др. 2012, рис. 4: 15; 6: 13, 14; Ашихмина, 2014, рис. 7-9, 11-12, $14,17,18)$. Близки им памятники сусканской культуры Самарского Поволжья и бассейна реки Сок (Колев, 1999, рис. 3-7; Колев, 2000, рис. 4-6). Отличие луговских и сусканских орнаментальных мотивов на керамике заключается в практически полном отсутствии на сусканских сосудах ямок в орнаментации. Гораздо меньше аналогий керамике Мальцевской IV стоянки прослеживается на поселениях Приказанского Поволжья балымскокарташихинского типа (Халиков, 1980, табл. 24, 57).

Индивидуальные находки выявлены в верхней части заполнения ямы 4. Это обломок керамического пряслица цилиндрической формы. Высота изделия 1,8 см, восстановленный диаметр 5,1 см, диаметр отверстия, имеющего коническую форму в сечении, $0,9-0,6$ см с разных сторон. Ближайшие аналогии пряслицам такой формы есть в древностях срубной культуры на различных поселенческих памятниках Поволжья: Найденное Озеро I (Барынкин и др., 2017, рис. 73: 7, 9), I Шигонское поселение (Кузьмина, 2017, рис. 26: 2, 3) и др. (Обыденнов, Обыденнова, 1992, рис. 45). Однако срубные пряслица с этих поселений более высокие, чем с Мальцевской IV стоянки. Наиболее близко мальцевскому пряслице, выявленное на срубном селище Светлое озеро в бассейне р. Кондурчи (Истомин и др., 2017, 
с. 504-505, рис. 5: 3). Схоже оно не только размерами, но и формой отверстия, имеющего усечено-коническую форму в сечении.

Миниатюрный сосудик из ямы 4 имеет баночную форму (рис. 6: 3). Диаметр по венчику 3 см, высота 1,9 см, диаметр дна 2,1-2,3 см. Он неорнаментирован, сделан небрежно, поверхность бугристая. Аналогии миниатюрным сосудикам широко известны в памятниках финала средней - начала поздней бронзы Южного Зауралья (Епимахов и др., 2012; Берсенева и др., 2014). Наиболее близкие аналогии данному сосуду выявлены в Поволжье на памятниках срубной культуры: Найденное Озеро I (Барынкин и др., 2017, рис. 73: 6), I Шигонское поселение (Кузьмина, 2017, рис. 71: 17, 18, 20, 21). Наиболее близок мальцевскому по форме сосудик из постройки сусканского времени Лебяжинка V (Кузьмина и др., 2017, рис. 7: 11). Однако вышеперечисленные аналогии при схожести форм все же больше по размерам, чем сосудик из Мальцевской IV стоянки. Наиболее вероятно, что миниатюрные сосудики эпохи бронзы изготовлялись детьми и были первыми пробными детскими керамическими поделками (Епимахов и др., 2012, с. 75; Берсенева и др. 2014, c. 96$)$.

По аналогиям в керамике Мальцевскую IV стоянку можно датировать эпохой поздней бронзы, луговской культурой, время существования которой в абсолютных калиброванных радиоуглеродных датах укладывается в промежуток XVII-XV вв. до н. э. (Лыганов, 2018, табл.).

Помимо керамики в раскопе на стоянке выявлено 28 костных фрагментов животных. Кости в слое стоянки сохранились плохо. В основном это зубы домашних животных. Костей КРС - 17 экз. и один зуб лошади. Еще десять - это неподдающиеся определению мелкие костяные обломки. В культурном слое зафиксировано 9 костей КРС, в сооружении 1 -6 зубов КРС и зуб лошади. Еще по одному фрагменту зуба КРС было выявлено в ямах 1 и 3.

Таким образом, изученный памятник Мальцевская IV стоянка -представляет собой интерес в первую очередь потому, что является, судя по археологическому материалу, однослойным, что достаточно редко встречается среди поселенческих памятников Прикамья. Культурный слой стоянки имеет небольшую мощность, что свидетельствует о кратковременности заселения данной территории.
С раскопа был собран представительный керамический материал, который полностью относится к луговской культуре, что неудивительно: Луговская I стоянка, по которой была названа культура, находится в непосредственной близи от Мальцевской IV стоянки всего в 5 км к югу. На Мальцевской стоянке не выявлено изделий из кремня, что также характеризует эту территорию и эту культуру, кремневые находки на поселениях и могильниках которой достаточно редки.

На памятнике изучены сооружения, заглубленные в материковый желто-коричневый суглинок. Интерес представляет сооружение 1, которое является заглубленной в землю каркасно-столбовой постройкой, супесчаное дно которой просело в результате утаптывания людьми или животными.

Вероятно, Мальцевская IV стоянка относится к категории временных поселений - летних лагерей для выпаса крупного рогатого скота. На это указывает ряд следующих фактов:

1. Стоянка находится на невысокой дюне в разрезе пойменной террасы, культурный слой достаточно слаб и содержит напластования только одной археологической культуры, что отличает стоянку от одновременных поселений региона с мощным культурным слоем, содержащим артефакты различных археологических культур, расположенных на надпойменных террасах. Это свидетельствует в пользу эпизодичного присутствия людей на Мальцевской IV стоянке.

2. В постройке отсутствует очаг, пол имеет корытообразное дно, образовавшееся, видимо, в результате утаптывания, возможно, крупным рогатым скотом. Ямы 2 и 3 незначительно заглублены и имеют такое же корытообразное дно, образовавшееся, вероятно, тоже в результате утаптывания грунта. На территории раскопа выявлено множество столбовых ям, которые, возможно, являются столбами от ограждений. Все это отличает постройку на Мальцевской стоянке от одновременных построек на поселениях региона, где отмечены значительно углубленные в материк полуземлянки с относительно ровным дном и выраженными стенами, с небольшим количеством столбовых ям в жилищах и практически полным отсутствием таковых за их пределами. В большинстве построек выявлены очаги.

Это позволяет сделать некоторые предварительные выводы о системе скотоводства носителей луговской культуры. Оно характе- 
ризуется придомным содержанием крупного рогатого скота в зимнее время и отгон стад на расстояние до 5-15 км в летнее время в богатые растительностью поймы рек. Для этих целей создавались «летники» - летние загоны для стада. Летник (или карда) представляет собой загон, ограждение которого сделано из деревянных жердей. С точки зрения типа построек летник можно считать каркасностолбовой конструкцией без крыши. Известны в современности и комбинированные летники, которые состоят из крытой части и загона без крыши (Рассадников, 2019, с. 181). Возможно, Мальцевская IV стоянка является остатком такого летника.

\section{ЛИТЕРАТУРА}

Ашихмина Л.И. Генезис ананьинской культуры в Среднем Прикамье (по материалам керамики и жилищ) / Археология Евразийских степей. Вып. 19. Казань: ИА АН РТ; Отечество, 2014. 300 с.

Барынкин П.П., Кузьмина О.В., Ластовский А.А. Поселение Найденное Озеро I // Вопросы археологии Поволжья. Вып. 6 / Отв. ред М.А Турецкий. Самара: Изд-во «Книжное Издательство». 2017. С. $7-108$.

Берсенева Н.А., Куприянова Е.В., Берсенев А.Г. Следы детства: поиск детей в археологическом источнике и изучение керамических артефактов (эпоха бронзы Южного Зауралья) // Вестник НГУ. Серия: История, Филология. 2014. т. 13. Вып. 3: Археология и этнография. С. 88-100.

Генинг В.Ф., Старостин П.Н. Кумысские стоянка и могильник // Отчеты Нижнекамской археологической экспедиции. Вып. 1. / Отв. ред. О.Н. Бадер. М.: Знание, 1972. С. 87-104.

Епимахов А.В., Берсенева Н.А., Пантелеева С.Е. Миниатюрные сосуды поселения Каменный Амбар // Уральский исторический вестник. 2012. № 4(37). С. 70-76.

Збруева A.B. Памятники эпохи поздней бронзы в Приказанском Поволжье и Нижнем Прикамье // МИА. № 80. М.: Наука, 1960. С. 10-95.

Истомин К.Э., Кочкина А.Ф., Салугина Н.П., Сташенков Д.А. Археологические исследования селища Светлое озеро в Нурлатском районе Республики Татарстан // Вопросы археологии Поволжья. Вып. 6. / Отв. ред М.А Турецкий. Самара: Изд-во «Книжное Издательство». 2017. С. 502-525.

Колев Ю.И. Керамические комплексы поселений позднего бронзового века в нижнем течении р. Сок // Вопросы археологии Поволжья. Вып. 1. / Отв. ред. А.А. Выборнов. Самара: Изд-во СамГПУ, 1999. Вып. 1. С. 249-269.

Колев Ю.И. Заключительный этап эпохи бронзы в Поволжье // История Самарского Поволжья с древнейших времен до наших дней. Бронзовый век / Ред. Ю.И. Колев, А.Е. Мамонов, М.А. Турецкий. Самара: СНЦ РАН. 2000. С. 242-273.

Кузьмина О.В. І Шигонское поселение // Вопросы археологии Поволжья. Вып. 6. / Отв. ред М.А Турецкий. Самара: Изд-во «Книжное Издательство». 2017. С. 279-390.

Кузьмина О.В., Колев Ю.И., Ластовский А.А., Туреикий М.А. Материалы эпохи бронзы поселения Лебяжинка V // Вопросы археологии Поволжья. Вып. 6. / Отв. ред М.А Турецкий. Самара: Изд-во «Книжное Издательство». 2017. С. 124-278.

Лыганов А.В. Андроноидные традиции в культурах позднего бронзового века лесостепного Поволжья // XXI Уральское археологическое совещание, посвященное 85-летию со дня рождения Г.И. Матвееевой и 70-летию со дня рождения И.Б. Васильева. Материалы Всероссийской научной конференции с международным участием. 8-11 октября 2018 г. / Отв. ред. А.А. Выборнов. Самара: Изд-во СГСПУ, ООО «Порто-Принт», 2018. С. 128-130.

Лыганов А.В., Морозов В.В., Азаров Е.С. Луговские I и II стоянки и проблема соотношения черкаскульской, луговской и межовской культур в Нижнем Прикамье // Археология Евразийских степей. 2019. №2. С. 38-98.

Обыденнов М.Ф. Агидельское поселение на Нижней Белой // Урало-Поволжская лесостепь в эпоху бронзового века/ Отв.ред. Т. Г. Обыденнова. Уфа: Изд-во БГПУ, 2006. С. 140-148. 
Обыденнов М.Ф., Обыденнова Г.Т. Северо-восточная периферия срубной культурно-исторической общности. Самара: Изд-во Саратов. ун-та, Самарск. Филиал. 1992. 172 с.

Рассадников А.Ю. Животноводство у населения Южного Зауралья в эпоху бронзы (по материалам поселений долин р. Карагайлы-Аят и Гумбейка). Дисс. ... канд. ист. наук. Екатеринбург, 2019. 235 с.

Свод памятников археологии Республики Татарстан: в 3 т. / Отв. ред. А.Г. Ситдиков, Ф.Ш. Хузин. Т. 3. Казань: ИИ АН РТ, 2007. 529 с.

Халиков А.Х. Приказанская культура / САИ. Вып. 1-24. М.: Наука, 1980. 128 с.

Чижевский А.А. Жилища и поселения лесной и лесостепной части Волго-Камья второй половины II - начала I тыс. до н.э. в контексте развития природной среды и культурных традиций // Археология и естественные науки Татарстана. Кн. 3 / Отв. ред. М.Ш. Галимова. Казань: Алма-Лит, 2007. С. 93-112.

Чижевский А.А., Лыганов А.В., Морозов В.В. Исследования памятников археологии на острове Дубовая грива в 2009-2010 гг. // Поволжская археология. 2012. № 1. С. 94-115.

\section{Информация об авторе:}

Лыганов Антон Васильевич, кандидат исторических наук, старший научный сотрудник Академии наук Республики Татарстан (г. Казань, Россия); liganov.anton@yandex.ru

\section{REFERENCES}

Ashikhmina, L. I. 2014. Genezis anan'inskoi kul'tury v Srednem Prikam'e (po materialam keramiki $i$ zhilishch) (Genesis of the Ananyino Culture in the Middle Kama Area (According to the Ceramics and Dwellings)). Series: Arkheologiia evraziiskikh stepei (Archaeology of the Eurasian Steppes) 19. Kazan: Institute of Archaeology named after A. Kh. Khalikov, Tatarstan Academy of Sciences; "Otechestvo" Publ. (in Russian).

Barynkin, P. P., Kuzmina, O. V., Lastovsky, A. A. In Turetskiy, M. A. (ed.). Voprosy arkheologii Povolzh 'ia (Issues on Archaeology of the Volga Region) 6. Samara: "Knizhnoe izdatel'stvo" Publ., 7-108 (in Russian).

Berseva N. A., Kupriyanova E. V., Bersnev A. G. 2014. In Vestnik Novosibirskogo Gosudarstvennogo universiteta. Istoriia, filologiya (Bulletin of the Novosibirsk State University: History, Philology) 13 (3), 88-100 (in Russian).

Gening, V. F., Starostin, P. N. 1972. In Bader, O. N. (ed.). Otchety Nizhnekamskoi arkheologicheskoi ekspeditsii (Reports of Lower Kama Archaeological expedition of the USSR Academy of Sciences). Issue 1, Moscow: "Znanie: Publ., 87-104 (in Russian)

Epimakhov A. V., Berseneva N. A., Panteleeva S. E. 2012. In Ural'skiy istoricheskiy vestnik (Ural Historical Journal) 37 (4), 70-76 (in Russian).

Zbrueva, A. V. 1960. In Materialy i issledovaniia po arkheologii (Materials and Studies in the Archaeology) 80. Moscow: "Nauka" Publ., 10-95 (in Russian).

Istomin, K. E., Kochkina, A. F., Salugina, N. P., Stashenkov, D. A. 2017. In Turetskiy, M. A. (ed.). Voprosy arkheologii Povolzh'ia (Issues of Archaeology of the Volga Region) 6. Samara: "Knizhnoye Izdatel'stvo" Publ., 502-525 (in Russian).

Kolev, Yu. I. 2000. In Kabytov, I. S. (ed.). Istoriia Samarskogo Povolzh'ia s drevneishikh vremen do nashikh dnei. Bronzovyi vek (History of the Samara Volga Region from the Most Ancient to Modern Times. The Bronze Age). Samara: Russian Academy of Sciences, Samara Scientific Center, 242-273 (in Russian).

Kolev, Yu. I. 1999. In Vybornov, A. A. (ed.). Voprosy arkheologii Povolzh'ia (Issues of Archaeology of the Volga Region) 1. Samara: Samara State Pedagogical University, 249-269 (in Russian).

Kuz'mina, O. V. 2017. In Turetskiy, M. A., (ed.). Voprosy arkheologii Povolzh'ia (Issues of Archaeology of the Volga Region) 8. Samara: Изд-во «Книжное Издательство», 279-390 (in Russian).

Kuz'mina, O. V., Kolev, Yu. I., Lastovsky A. A., Turetskiy, M. A. 2017. In Turetskiy, M. A., (ed.). Voprosy arkheologii Povolzh'ia (Issues of Archaeology of the Volga Region) 8. Samara: "Knizhnoye Izdatel'stvo" Publ., 124-278 (in Russian).

Lyganov, A. V. 2018. In Vybornov, A. A. (ed.). XXI Ural'skoe arkheologicheskoe soveshchanie (21th Urals Archaeological Congress)). Samara: "Samara State University of Social Sciences and Education", "PortoPrint" Publ., 128-130 (in Russian).

Lyganov, A. V., Morozov, V. V., Azarov, E. S. 2019. In Arkheologiia Evraziiskikh stepei (Archaeology of Eurasian Steppes) 2. 38-98 (in Russian). 
Obydennov, M. F. 2006. In Obydennova, T. G. (ed.). Uralo-Povolzhskaia lesostep' v epokhu bronzovogo veka (Ural-Volga Forest-Steppe Area in the Bronze Age). Ufa: Bashkirian State Pedagogical Institute Publ., 140-148 (in Russian).

Obydennov, M. F., Obydennova, G. T. 1992. Severo-vostochnaja periferiia srubnoi kul'turno-istoricheskoi obshhnosti (North-Eastern Periphery of the Srubna Cultural and Historical Community). Samara: Saratov Satte University, Samara branch Publ. (in Russian).

Rassadnikov, A.Yu. 2019. Zhivotnovodstvo u naselenija Juzhnogo Zaural'ja v jepohu bronzy (po materialam poselenij dolin r. Karagajly-Ajat i Gumbejka). (Cattle Breeding among the Population of the Southern Trans-Urals in the Bronze Age (based on Materials from Settlements in the Valleys of the KaragaillyAyat and Gumbeyka Rivers).) Diss.of candidate of historical Sciences. Yekaterinburg (in Russian).

Sitdikov, A. G., Khuzin F. Sh. (eds.). 2007. Svod pamiatnikov arkheologii Respubliki Tatarstan (Corpus of Archaeological Sites in the Republic of Tatarstan) 3. Kazan: Institute for History named after Shigabuddin Mardzhani, Tatarstan Academy of Sciences of the Republic of Tatarstan (in Russian).

Khalikov, A. Kh. 1980. Prikazanskaia kul'tura (ThePrikazanskaya Culture). Series: SvodArkheologicheskikh Istochnikov (Corpus of Archaeological Sources) 1-24. Moscow: "Nauka" Publ. (in Russian).

Chizhevsky, A. A, 2007. In Galimova, M. Sh. (ed.). Arkheologiia i estestvennye nauki Tatarstana (Archaeology and Natural Sciences of Tatarstan) 3. Kazan: "Foliant" Publ., 336-367 (in Russian).

Chizhevsky, A. A., Lyganov, A. V., Morozov, V. V. 2012. In Povolzhskaia arkheologiia (Volga River Region Archaeology) (1), 94-115. (in Russian).

\section{About the Author:}

Lyganov Anton V. Candidate of Historical Sciences. Institute of Archaeology named after A. Kh. Khalikov, Academy of Sciences of the Republic of Tatarstan. Butlerov St., 30, Kazan, 420012, Republic of Tatarstan, Russian Federation; ligaant@rambler.ru

Статья поступила в журнал 01.08.2020 г. Статья принята к публикации 01.09.2020 г.

Распределение находок в раскопе на Мальцевской IV стоянке

Таблицุа 1

Distribution of findings in the excavation at the Maltsevo IV site.

Table 1.

\begin{tabular}{|l|l|}
\hline Глубины и сооружения & Керамика. луговская культура \\
\hline $0-20$ см & 68 \\
\hline $20-40$ см & 355 \\
\hline Соор. 1. & 168 \\
\hline Соop. 2. & 49 \\
\hline Соор.3. & 6 \\
\hline Соор.4. & $6+$ целый миниатюрный сосудик+ фрагмент напрясла \\
\hline С. я. 3. & 28 \\
\hline С. я. 4. & 5 \\
\hline Всего & 686 \\
\hline
\end{tabular}



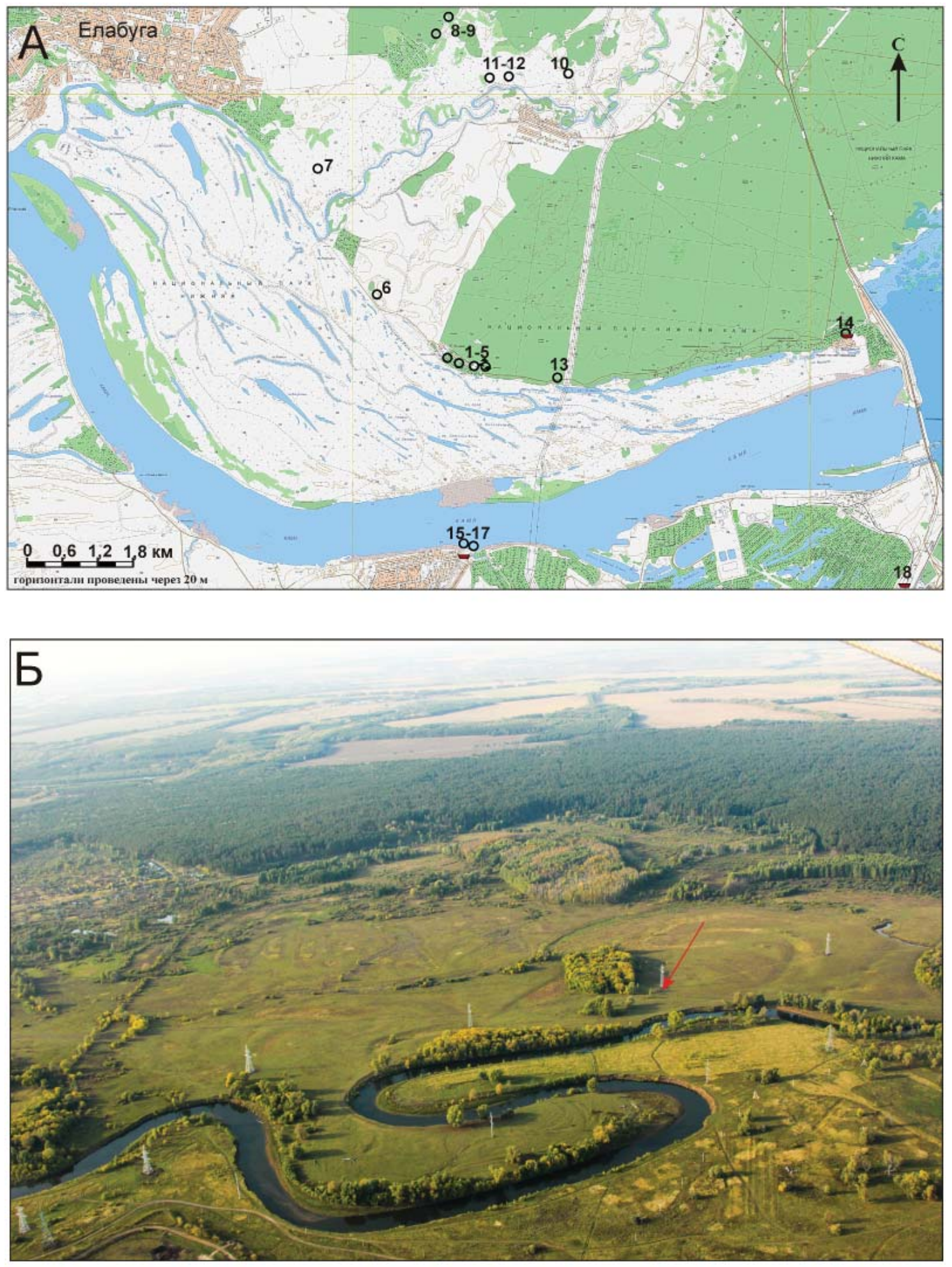

Рис. 1. А - План округи Мальцевской IV стоянки с памятниками позднего бронзового века: $1-5$ - Луговские I-IV стоянки и Луговской курганный могильник; 6 - поселение бронзового века на Ананьинской дюне; 7 - Елабужские стоянки; 8-10 - Мальцевские I-III стоянки; 11-12 - Мальцевская IV-V стоянка; 13 -

Отарнинская стоянка; 14 - Кумысская стоянка и могильник; 15-17 - Бетькинские стоянки и могильник; 18 -

Набережночелнинский могильник. Б - Аэрофотоснимок Мальцевской IV стоянки с юго-востока.

Fig. 1. A - Layout of the neighbouring area of Maltsevo IV site with Late Bronze Age monuments: 1-5 - Lugovskoe I-IV sites and the Lugovskoj burial mound ground; 6 - Bronze Age settlement on the Ananyino dune; 7 - Yelabuga sites; 8-10 - Maltsevo I-III sites; 11-12 - Maltsevo IV-V site; 13 - Otary site; 14 - Kumys site and burial ground; 15-17 - Bet'ki sites and burial ground; 18 - Naberezhnye Chelny burial mound. B - Aerial view of Maltsevo IV site from the south-east. 

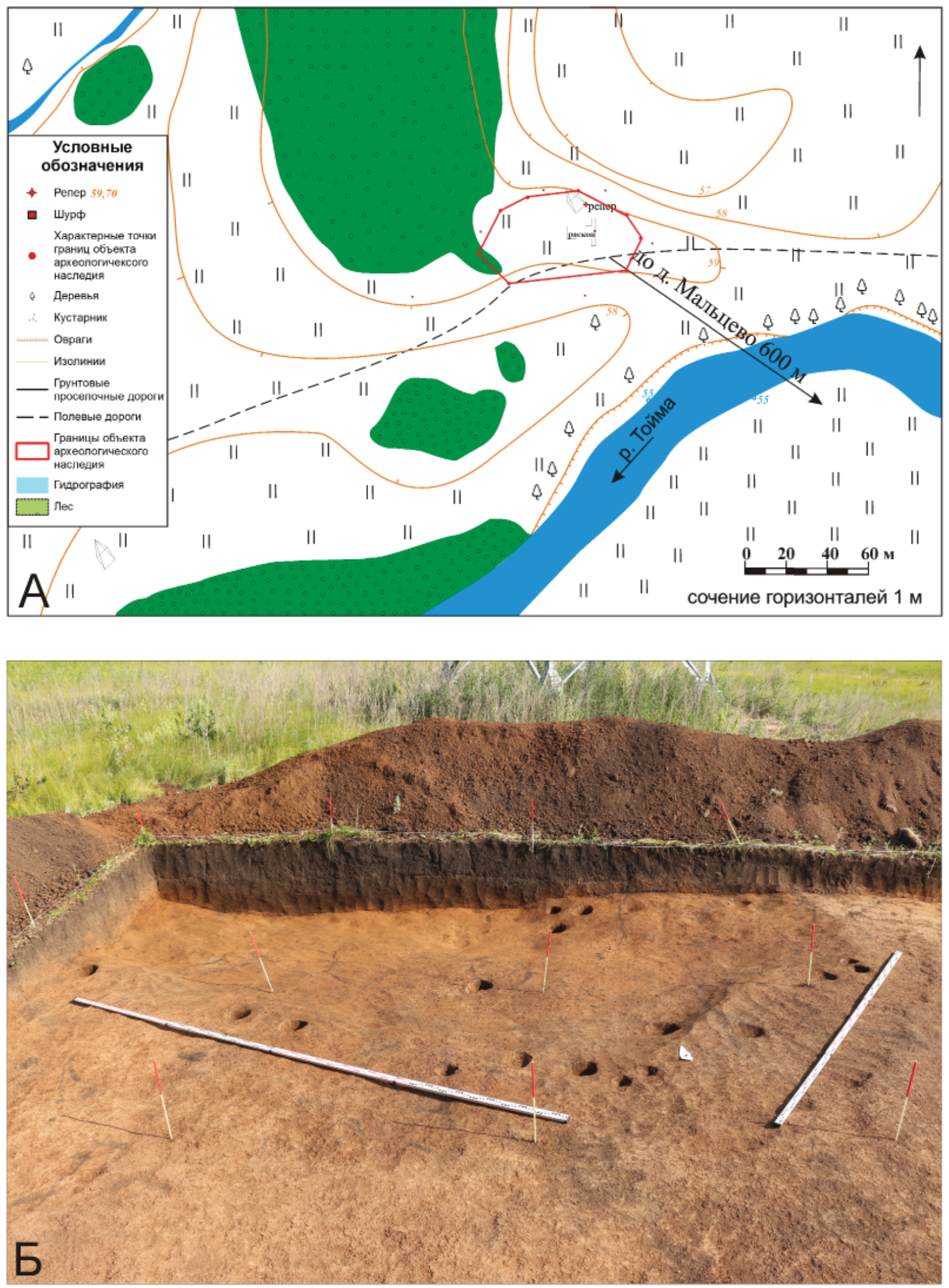

Рис. 2. А - План Мальцевской IV стоянки с нанесенным раскопом. Б - Фото котлована сооружения 1. Вид с юга. Fig. 2. A - Layout of Maltsevo IV site with an indicated excavation. B - Photograph of construction pit 1. View from the south. 

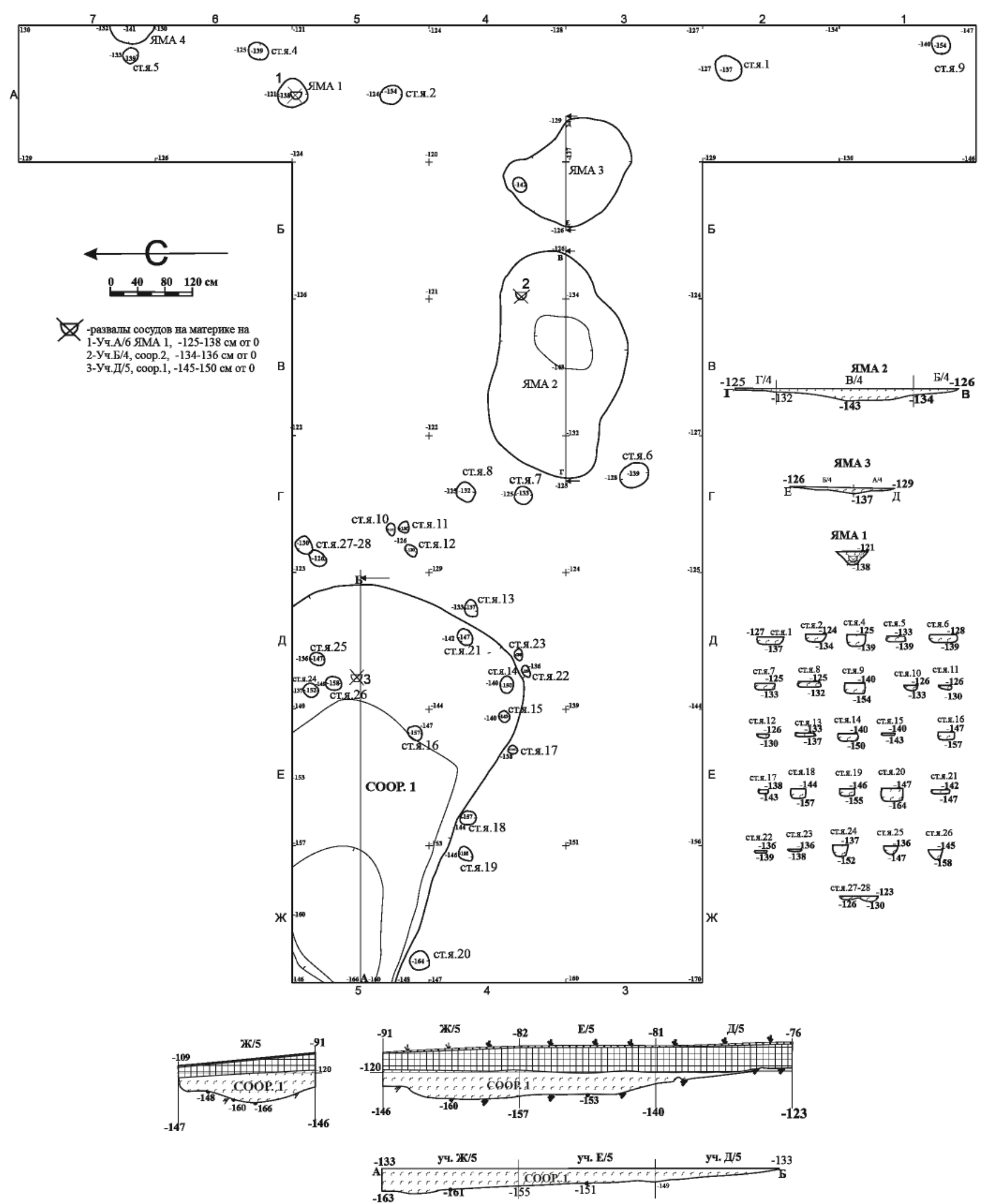

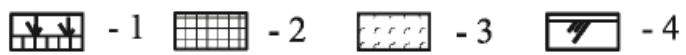

Рис. 3. План раскопа Мальцевской IV стоянки на уровне материка и профиля сооружений и ям.

Условные обозначения: 1 - дерн, 2 - плотная темно-серая гумусированная супесь, 3 - серая гумусированная супесь с включением угольков, 4 - материк.

Fig. 3. Excavation plan of Maltsevo IV site at natural ground level and the profile of structures and pits.

Legend: 1 - sod, 2 - dense dark gray humified sandy loam, 3 - gray humous sandy loam with coal inclusions, 4 - natural ground. 


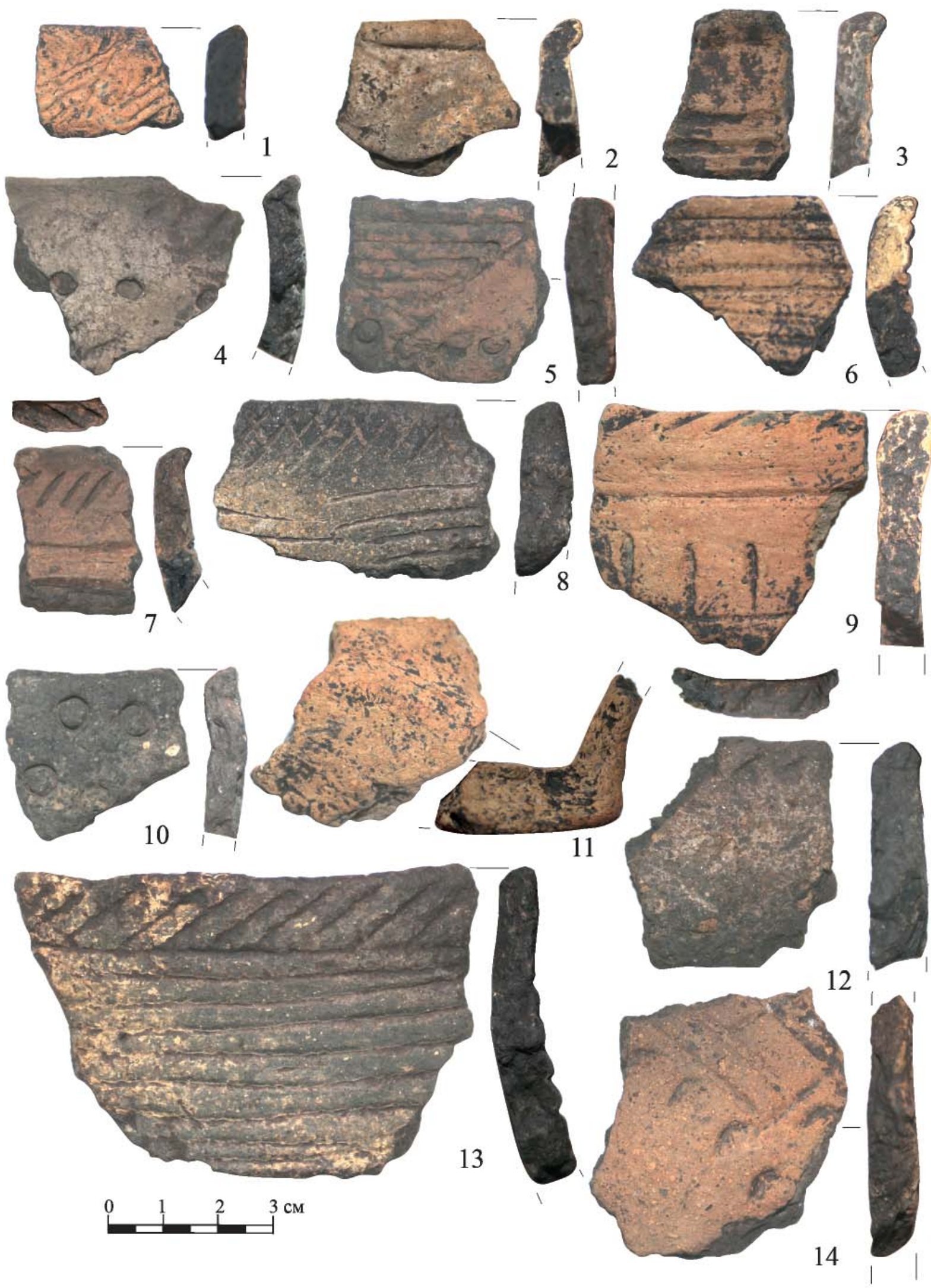

Рис. 4. Фрагменты лепной керамики луговской культуры. 1 - Уч. В/3, гл. 0-20 см; 2 - Уч. А/6, гл. 20-40 см; 3-5,7,8 - Уч. А/5, гл. 20-40 см; 6,11,13 - Уч. А/2, гл. 0-20 см; 9,10 - Уч. А/6, гл. 20-40 см; 12 - Уч. Ж/3, гл. 20-40 см; 14- Уч. В/3, гл. 20-40 см.

Fig. 4. Fragments of moulded ceramics of the Lugovskaja culture. 1 - Area V/3, depth 0-20 cm; 2 - Area A/6, depth 20-40 cm; 3-5, 7, 8 - Area A/5, depth 20-40 cm; 6, 11, 13 - Area A/2, depth 0-20 cm; 9, 10 - Area A/6, depth 20-40 cm; 12 - Area Zh/3, depth 20-40 cm; 14 - Area V/3, depth 20-40 cm. 


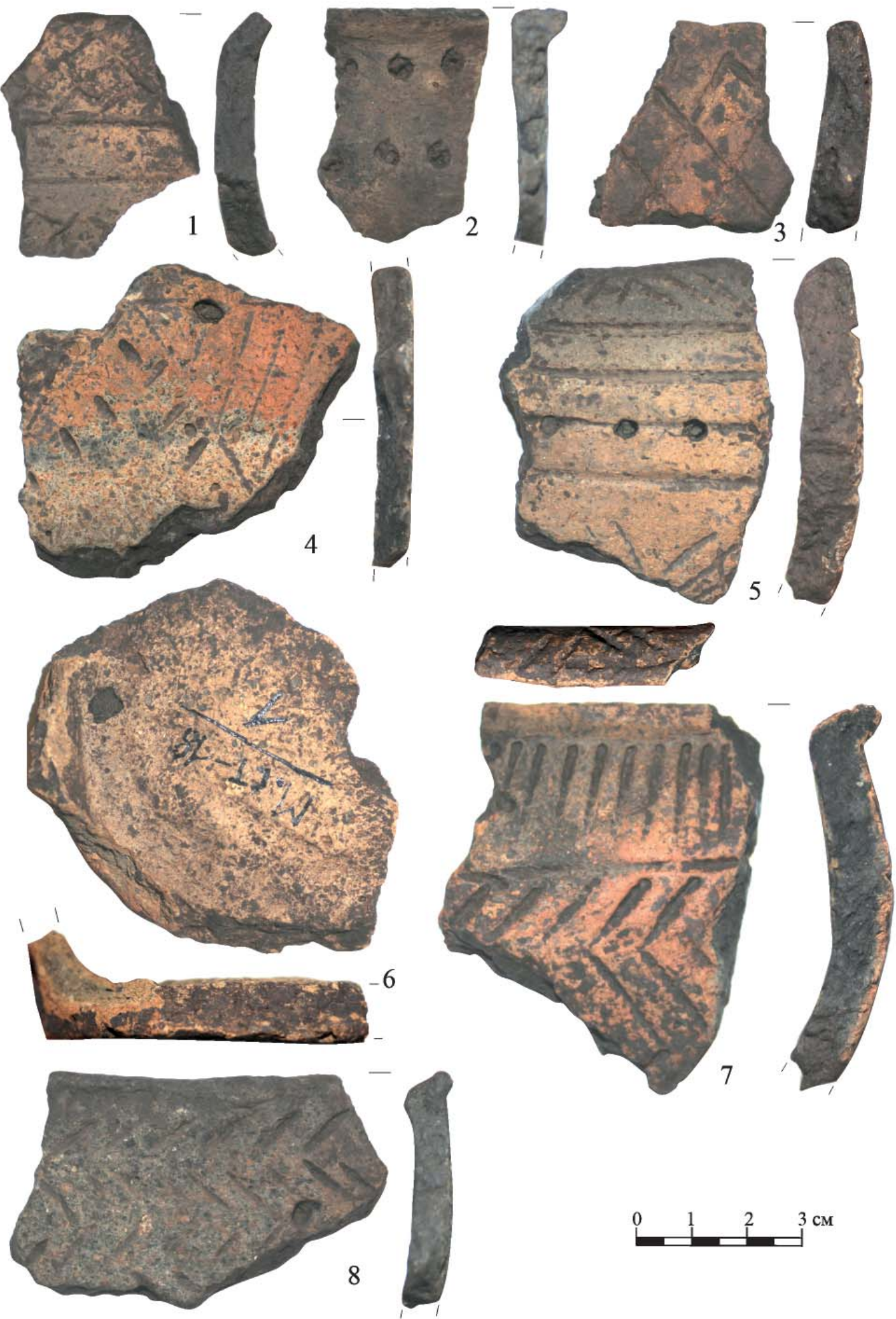

Рис. 5. Фрагменты лепной керамики луговской культуры. 1, 7 - Уч. Г/4, гл. 20-40 см; 2,4,5 - Уч. Г/5, гл. 20-40 см; 3 - Уч. Д/4, гл. 20-40 см; 6 - Уч. А/2, гл. 20-40 см; 8 - Уч. В/4, гл. 20-40 см.

Fig. 5. Fragments of moulded ceramics of the Lugovskaja culture. 1, 7 - Area G/4, depth 20-40 cm; 2, 4, 5 - Area G/5, depth 20-40 cm; 3 - Area D/4, depth 20-40 cm; 6 - Area A/2, depth 20-40 cm; 8 - Area V/4, depth 20-40 cm. 

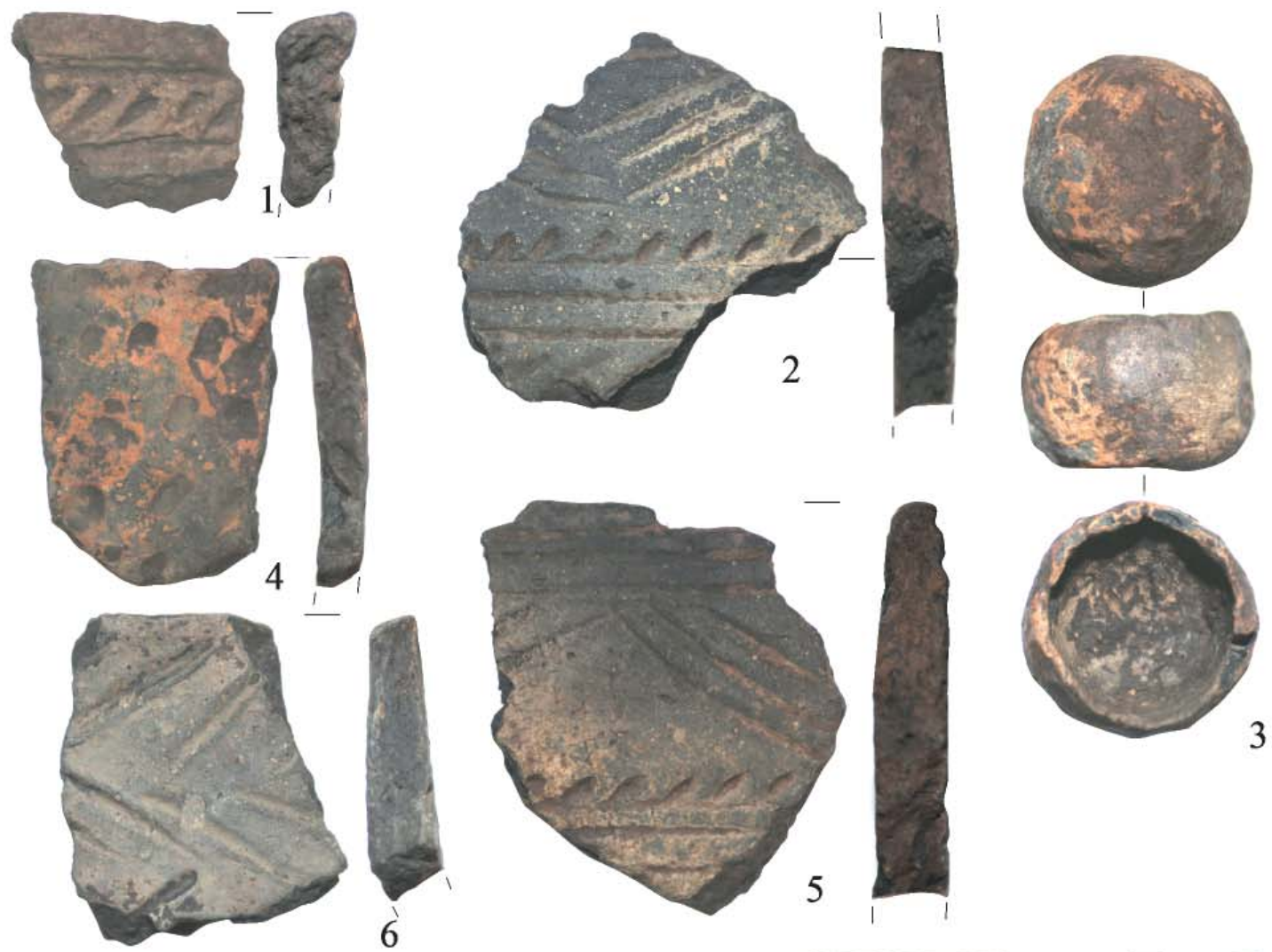

6
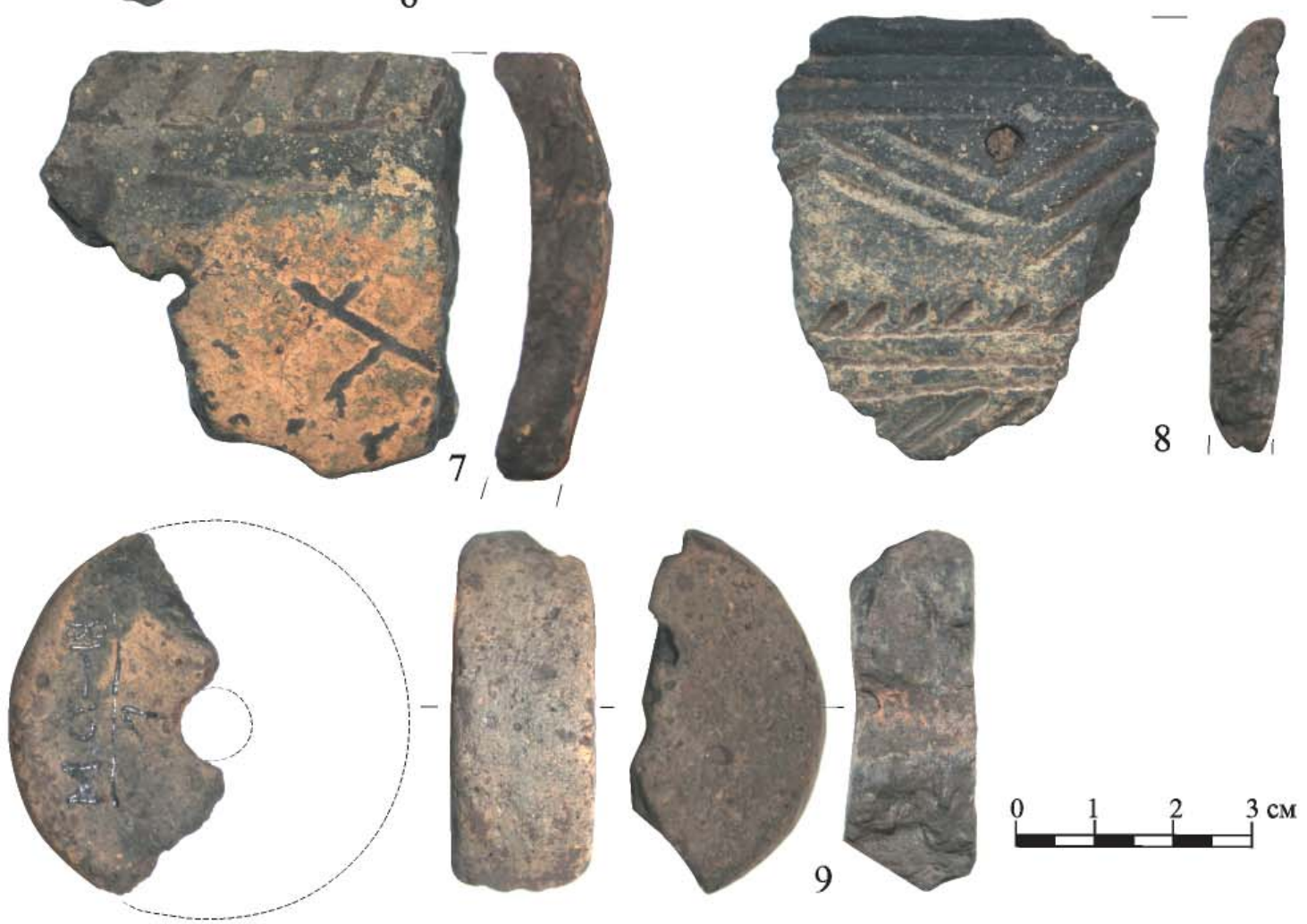

Рис. 6. Фрагменты лепной керамики луговской культуры из слоя и из заполнения ям. 1 - Уч. А/2, гл. 20-40 см; 4,6,7 - Уч. А/3, гл. 20-40 см; 2,5,8 - Уч. Б/4, Яма 2, развал, гл. 45-55 см; 3,9 - Яма. 4, уч. А/7, гл. 20-40 см: 3 мелкий сосудик и 9 - фрагмент напрясла.

Fig. 6. Fragments of moulded ceramics of the Lugovskaja culture from the layer and pit filling. 1 - Area A/2, depth 20$40 \mathrm{~cm} ; 4,6,7$ - Area A/3, depth 20-40 cm; 2, 5, 8 - Area B/4, Pit 2, collapsed, depth 45-55 cm; 3, 9 - Pit. 4, area A/7, depth 20-40 cm: 3 - small vessel and 9 - fragment of a spindle whorl. 


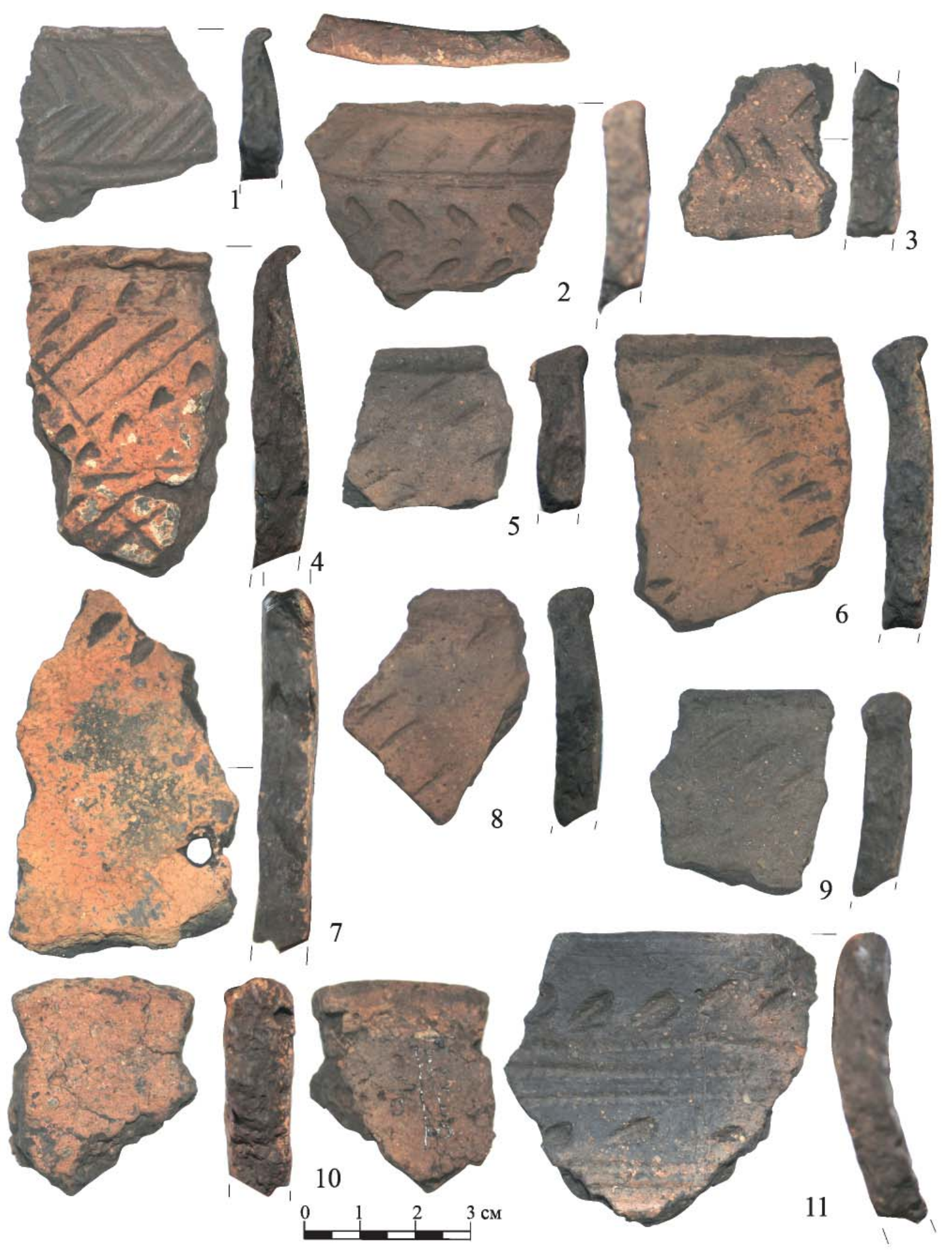

Рис. 7. Фрагменты лепной керамики луговской культуры из заполнения сооружения 1. 1,4 - Уч. Е/5, гл. 40-60 см; 2,3,7,11 - сооружение 1 , Уч. Д/5, гл. 40-55 см; 5,6,8-10 - Уч. Д/5, гл. 40-45 см, развал сосуда и фрагмент глиняного диска?

Fig. 7. Fragments of moulded ceramics of the Lugovo culture from the filling of construction 1. 1, 4 - area E/5, depth 40-60 cm; 2,3,7,11 - construction 1, area D/5, depth 40-55 cm; 5,6,8-10 - area D/5, depth 40-45 cm, collapsed vessel and a fragment of a clay disc. 

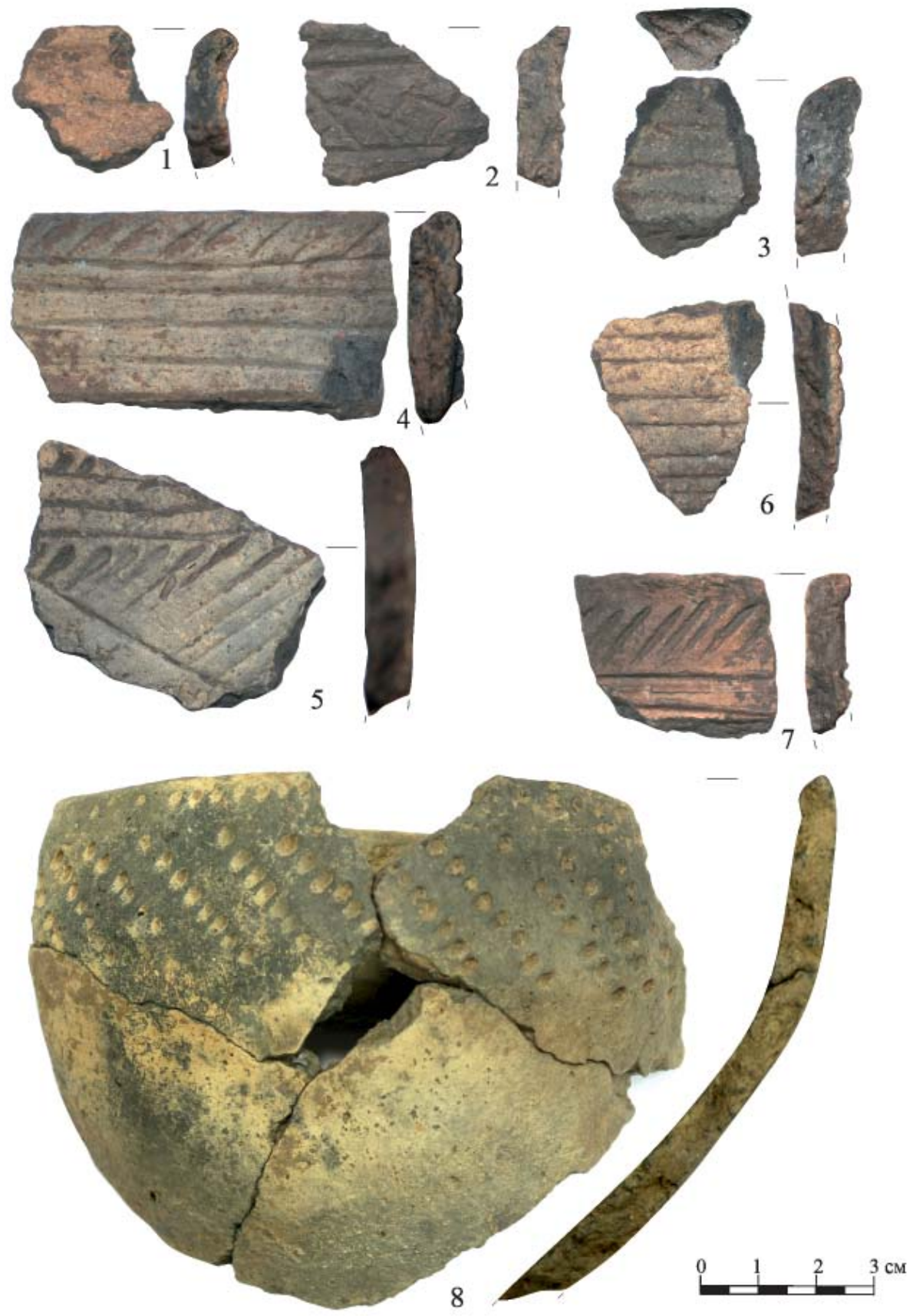

Рис. 8. Скопление керамики и развал сосуда луговской культуры. Яма 1. Уч. А/6, гл. 40-60 см. Fig. 8. Cluster of ceramics and a collapsed vessel of the Lugovskaja culture. Pit 1. Area A/6, depth 40-60 cm. 